\title{
Counterfactuals, Temporal Adverbs, and Association with Focus
}

\author{
Toshiyuki Ogihara \\ University of Washington
}

\section{Introduction}

This paper discusses counterfactual conditionals like (1a-b) in which the time indicated by the tense morpheme(s) and the time denoted by the co-occurring temporal adverb do not match.

a. If John had given flowers to Mary TOMORROWF, she would have been pleased.

b. If we had gone out for a walk TOMORROW time.

Suppose that Mary's birthday is tomorrow, but her boyfriend John thought it was yesterday and gave flowers to her yesterday. Mary was so disappointed that John was mistaken about her birthday and she was not even pleased with the flowers she received. (1a) says therefore that if we assume counterfactually that the "same thing" happens tomorrow instead of yesterday, then Mary is pleased then (i.e., tomorrow). Note here that since Mary is already disappointed, it is too late for John to do the "same thing" (i.e., giving flowers to Mary) again tomorrow and please Mary. Put another way, two times are competing for the time of John's giving flowers to Mary, and the time at which this actually took place must be located in the past. (1b) makes the same point. Suppose that we were able to go out for a walk only once (within a contextually determined set of alternative dates) because of scheduling constraints and that today and tomorrow were the only two alternative possibilities. We decided to go out today, did so, and got rained on. Now the weather forecast says that tomorrow is guaranteed to be a sunny day. In this situation, (1b) seems to be true. In both (1a) and (1b), the temporal adverb tomorrow is said to be "focused" in that it has intonational prominence. This is indicated by a subscripted F in (1). This type of example is not discussed explicitly in previous proposals such as Stalnaker (1968), Lewis (1973) and Kratzer (1981, 1989). Rooth (1985) discusses some examples of counterfactuals with a focused constituent in the antecedent and proposes an account on the basis of Kratzer's (1981) proposal, but his examples do not involve focused temporal adverbs. This paper presents a proposal that modifies the Kratzer-Rooth account to accommodate data such as $(1 a-b)$.

The basic intuition about counterfactual conditionals is relatively straightforward. The antecedent of a counterfactual conditional normally posits a contrary-to-fact situation and draws some conclusion from this supposition. ${ }^{1}$ When we go through this reasoning, we make minimal adjustments to the actual world necessary to make the proposition given by the antecedent true, and then assert that the consequent is true in this hypothetical situation. Kratzer (1981) expresses her intuitions as in (2). 
(2) The truth of counterfactuals depends on everything which is the case in the world under consideration: in assessing them, we have to consider all the possibilities of adding as many facts to the antecedent as consistency permits. If the consequent follows from every such possibility, then (and only then), the whole counterfactual is true.

English conditionals of the form (3a) normally introduce counterfactual situations located in the past as in (3b) and are referred to as past counterfactuals. I say "normally" because (1a-b) do not conform to this generalization in that they introduce counterfactual situations in the future.

a. If ... had p.p. ..., ,.. would have p.p. ... (where p.p. indicates the past participial form of a verb)

b. If John had been rich, he would have been happy.

A question naturally arises as to why the past perfect rather than the simple past is used to indicate a counterfactual situation in (3b). In this connection, we should also examine present counterfactuals which are schematized in (4a) and are exemplified by (4b).
a. If ... V-ed. ..., ... would V. ... (where V-ed indicates the past tense form of a (stative) verb, and V indicates the infinitival form of a (stative) verb)
b. If John were rich, he would be happy.

We clearly find a pattern in (3) and (4). The antecedent of (4b) posits a counterfactual situation at the utterance time but is in the simple past tense, whereas the antecedent of ( $3 \mathrm{~b}$ ) establishes a counterfactual situation at some (contextually salient) past time but is in the past perfect. ${ }^{2}$ Iatridou (2000) claims that the past tense as used in (3b) and (4b) is "fake" in that it does not convey the meaning of anteriority. Instead, it has the meaning of being evaluated at a world different from the actual world. This can be taken to mean roughly that the past is responsible for conveying a counterfactual implicature. This in turn means that the perfect is used in past counterfactuals to indicate anteriority.

Iatridou's account of tense morphemes in counterfactuals is consistent with what is implicitly assumed in the previous proposals about counterfactuals. For example, Lewis (1973) posits the counterfactual conditional connective $\square \rightarrow$, which produces formulas such as (5a). This translates the English counterfactual (5b) and reads officially as 'If it were the case that John is rich, then it would the case that he is happy.' 3

a. John is rich $\square \rightarrow$ John is happy

b. If John were rich, he would be happy.

This analysis indicates that the past tense in the antecedent and the auxiliary would in the consequent are used for indicating counterfactuality and not anteriority. The present tense in (5a) or its paraphrase indicates that the temporal location of whatever the antecedent describes is the utterance time. By extending this general 
idea, Lewis informally presents the case of past counterfactuals in the following way.

a. John was rich $\square \rightarrow$ John was happy

b. If John had been rich, he would have been happy.

Lewis's “official English reading" of (6a) is 'If it were the case that John were rich, it would be the case that John was happy'. Lewis is of course aware that this is a sentence "obscure in meaning and of doubtful grammaticality" if it is understood to be a colloquial English sentence. (6a) corresponds to the colloquial English conditional (6b), which is derived in the following way according to Lewis: "the subjunctive 'were' of the counterfactual construction and the "were' of the antecedent are transformationally combined into a past subjunctive." Thus, Lewis's idea about the semantic contribution of tense morphemes in counterfactual conditionals is very close to Iatridou's.

Given the above informal discussion, it seems reasonable to posit the truth conditions (7) for (3a) combining the ideas of Lewis (1973) and Iatridou (2000).

(7) A conditional of the form "If A had V1-ed, B would have $\mathrm{V}^{2}$-ed" is true in $w_{c}$ at $t_{\mathrm{c}}$ iff at some contextually salient time $t$ earlier than $t_{\mathrm{c}}$ in $w_{\mathrm{c}}$, all worlds $w$ closest to the actual world $w_{\mathrm{c}}$ in terms of a similarity hierarchy among those in which " $\mathrm{A} \mathrm{V}^{1}$ " (tenseless) is true at $t$, it follows that " $\mathrm{B} \mathrm{V}$ " (tenseless) is true at $t$ in $w$.

Note: $t_{\mathrm{c}}$ and $w_{\mathrm{c}}$ indicate the utterance time and the actual world, respectively.

(7) accounts for (3b). However, (7) has problems with (1a-b).

The first problem with (7) is its requirement that the counterfactual situation be located in the past. (1a-b) violate this requirement because the adverb tomorrow clearly denotes a future time. ${ }^{4}$ It is not that the proposal given in (7) is completely off the mark, however. Intuitively, (1a-b) are analogous to other past counterfactuals such as (8), in which a name is focused, in that they make reference to some relevant past situations.

(8) If BILLF had given flowers to Mary, she would have been pleased.

A counterfactual such as (8) in which a non-temporal expression is focused leads us to believe that what is located in the past is what the antecedent describes (i.e., an event of Bill's giving flowers to Mary). However, this hypothesis does not cover all examples of counterfactuals that conform to the schema in (3a); we have already seen that in (1a-b), what is described by the antecedent is located in the future. I hypothesize that the perfect does not indicate the time of the hypothetical eventuality described by the antecedent. ${ }^{5}$ Rather, it indicates the time of an eventuality that obtains in the actual world and is contrasted with the antecedent eventuality. ${ }^{6}$ For example, the contextually salient past time for (8) is understood to be the time at which someone other than Bill gave flowers to Mary. Although the time of Bill's giving flowers to Mary is interpreted to be simultaneous with this time, I argue that this result is obtained indirectly through the use of a covert adverb then. This 
analysis is motivated by examples like $(1 \mathrm{a}-\mathrm{b})$ but can also be used for examples like (8). We will formalize this idea below.

Another possible problem with (7) is that it might not make the right predictions as to which worlds are closest to the actual one in terms of a relevant similarity hierarchy. For example, it is arguable that in (1a) the worlds in which John gave flowers to Mary yesterday and will give some more tomorrow are more similar to the actual one than those in which John did not give any flowers to her yesterday and will give some tomorrow. However, the empirical data tell us otherwise. The consequent must be evaluated in worlds where John gives flowers to Mary tomorrow and not yesterday. This is puzzling because it is certainly not impossible for John to give flowers to Mary at these two relevant times. As mentioned earlier, It is reasonable to conclude that John's giving flowers to Mary yesterday and tomorrow does not make Mary happy since the fact remains that John was wrong about Mary's birthday. Even if Mary gets happier by receiving more flowers tomorrow, this does not seem to be the point of the counterfactual in question. Intuitively, what we need to do with regard to (1a) is to imagine a world in which John gives flowers to Mary tomorrow instead of yesterday. The same point can be made with (1b), going out for a walk today and tomorrow does not allow us to have a good time overall. This must receive some explanation.

Another fact worth noting here is that the type of interpretation that $(1 \mathrm{a}-\mathrm{b})$ receive is truly counterfactual in that $(9 a-b)$ would not be appropriate in the contexts in question.

a. If John gave flowers to Mary TOMORROWF, she would be pleased.

b. If we went out for a walk TOMORROWF, we would have a good time.

(9a-b) exemplify what Iatridou (2000) refers to as future less vivid conditionals. They would be appropriate in circumstances where John's giving flowers to Mary tomorrow (or our going out for a walk tomorrow) is unlikely but is not completely ruled out. This type of supposition is very different from what you find in counterfactual conditionals. More importantly, the proposition described by the antecedent is not contrasted with any proposition that was true in the actual world. Thus, (9a-b) and (1a-b) cannot be used interchangeably. The presence of an (actual) eventuality that is contrasted with the hypothetical eventuality is probably not a necessary condition for a felicitous use of a counterfactual conditional even when it contains a focused constituent. However, it is arguably a sufficient condition for a felicitous use of a counterfactual conditional. For example, (1a-b) are clearly counterfactual in that the speaker posits a contrary-to-fact situation and attempts to draw a conclusion from it. For example, (1a) can be used when John actually gave flowers to Mary yesterday. The counterfactual situation being entertained is one in which John gives flowers to Mary tomorrow instead of yesterday. The idea is that these two situations (one real and one hypothetical) are identical in all relevant respects except that they take place at different times. They are identical in that John is giving flowers to Mary intending to celebrate her birthday.

When the antecedent of a counterfactual contains a non-temporal focused constituent, two situations being compared often involve the same individual(s) and have the same temporal extension. Therefore, they are assumed to be mutually 
exclusive for pragmatic reasons. For example, assume that in (10) John actually went to Tavern A.

If John had gone to [TAVERN B]F, he would have had a good time.

The default assumption here is that John chooses one tavern among some alternatives and goes there. In this case, by assuming counterfactually that he went to Tavern B, one automatically excludes the possibility that he went to Tavern A. However, if we complicate the scenario slightly, we can easily imagine a situation in which John goes to both Tavern A and Tavern B. For example, we could assume that John was taking part in a pub crawl in which he and his friends visits many taverns in a single evening. In this case, John can go to Tavern B in addition to others. Thus, it is doubtful that pragmatics alone can account for the strongly preferred reading of (10): If John had gone to Tavern B instead of some other place(s), he would have had a good time.

It is true that the above examples of counterfactuals require that they be used in a context in which two or more alternative possibilities are compared. However, this seems to stem from the nature of the focus structure of the conditional in question rather than from purely pragmatic factors. In the rest of the paper, I will show how the focus-related information in counterfactuals is exploited to account for their overall interpretation.

\section{Kratzer's Theory of Counterfactual Conditionals and Rooth's Theory of Focus}

This section first discusses Kratzer's (1981) theory of counterfactuals. Then we will see how Rooth (1985) combines his theory of focus with Kratzer's theory of counterfactuals to account for the semantic effects of focus in counterfactuals.

In formalizing her theory, Kratzer (1981) posits a function $f$ that selects for any world $w$ the set of all propositions that are "the case" in $w^{7}$ Given this function $f, A_{w}(p)$ for any proposition $p$ and world $w$ is defined as the set of all consistent subsets of $f(w) \cup\{p\}$ which contain $p$. We can then say that a counterfactual conditional of the form "if $\mathrm{p}, \mathrm{q}$ " is true in $w$ iff the truth of $q$ follows from every maximal set in $A_{w}(p)$ (assuming that maximal sets of propositions exist in $A_{w}$ $(p)) .{ }^{8}$ Kratzer says that $f$ must be a partition function such that for any world $w$, $\cap f(w)=\{w\}$. That is, $f(w)$ must be a set of propositions that characterize the world $w$ uniquely. If we adopt this idea, a question arises as to how we determine what propositions to keep and what propositions to get rid of. Kratzer attempts to "kick out" some propositions by adopting the idea that some propositions lump together. For example, assume that Hans and Babette spent the evening together by going to a restaurant called "Dutchman's Delight." Given this fact, suppose counterfactually that Babette had gone to a bistro called "Frenchman's Horror" instead. We seem to be justified in concluding from this supposition that Hans would have gone there, too. This follows from Kratzer's proposal if we assume that $f\left(w_{c}\right)$ (where $w_{c}$ indicates the actual world) includes the proposition "Babette and Hans spent the evening together." If this proposition is an element of $f\left(w_{c}\right)$, then this amounts to lumping together the propositions "Hans went to Dutchman's Delight" and "Babette went to Dutchman's Delight." That is, if one of these propositions was false, then 
the other would have to be false as well. Given this supposition, we can conclude that (11) is true in the situation under consideration as desired.

If Babette had gone to Frenchman's Horror, Hans would have gone there, too.

Note that (11) contains a focused constituent, namely Frenchman's Horror. The fact that this constituent is focused is clearly related to the fact that Frenchman's Horror is contrasted with Dutchman's Delight. In general, when a counterfactual conditional contains a focused constituent in its antecedent, we can predict which proposition should be gotten rid of by paying attention to the focus-related information available in the conditional. Let us consider $(12 a-b)$, which differ from each other only with respect to focused constituents.

a. If John had married SUSANF, he would have been happy.

b. If John had MARRIEDF Susan, he would have been happy.

(12a) strongly implicates that John actually married someone other than Susan. We then go through the following reasoning: Suppose counterfactually that John had married Susan. Then can we conclude from this assumption that he would have been happy? On the other hand, (12b) is felicitous only if John actually had some non-matrimonial personal relationship with Susan. (His having married to someone other than Susan is not required.) We then reason as follows: Suppose counterfactually that John had married Susan. Can we conclude that he would have been happy then? In this way, the semantic difference between (12a) and (12b) clearly stems from the intonational difference between them. The generalization that emerges from an examination of such examples is that the proposition that is "kicked out" from the set of propositions against which the consequent is examined is obtained by replacing the focused expression in the antecedent with an expression of the same semantic type.

We should now discuss how to account for focus-related facts in counterfactuals within a Kratzer-type proposal. As mentioned earlier, the fact that a proposition contrasted with the one given by the antecedent is kicked out cannot be explained in terms of pragmatics alone. There are many instances in which the proposition described in the antecedent of a conditional is consistent with the proposition that is contrasted with what the antecedent conveys and is true in the actual world. In other words, we could entertain the possibility that two competing propositions are both true. Consider examples like those in (13).

(13) a. If John had drank SOFT DRINK $F$ at the party, he would not have had a hangover.

b. If I had asked MARYF for help, I would have finished the book in time.

The intended interpretation of (13a) is clear. However, assuming that John actually drank wine at the party, it is not clear why the counterfactual assumption that he drank soft drink precludes his drinking wine as well. One can certainly drink soft drink as well as wine at the same party. This in turn means that it is not obvious how the proposition "John drank wine" is kicked out from all maximal sets in $A_{w_{c}}$ ("John drank soft drink at the party"). In (13b), assume that the speaker 
actually asked Sue for help. Intuitively, the consequent must be evaluated in worlds in which the speaker asked Mary for help and not others. It is clear, however, that the speaker could have asked two people simultaneously for help. Kratzer's proposal appeals to the lumping of two relevant propositions in each case to account for its interpretation. In (13a) we would probably need to say that the proposition "John drank only one type of drink at the party" is an element of $f\left(w_{c}\right)$. This has the effect of lumping together "John drank soft drink" and "John did not drink wine," for example. In (13b), "I asked only one person for help" would be in $f\left(w_{c}\right)$, which has the effect of lumping together "I asked Mary for help" and "I did not ask Sue for help," for example.

The temporal examples in (1a-b) (repeated here as $(14 a-b))$ have exactly the same characteristic as non-temporal examples except that the mutually exclusive nature of the two propositions in temporal examples is more surprising than nontemporal ones.

a. If John had given flowers to Mary TOMORROWF, she would have been pleased.

b. If we had gone out for a walk TOMORROWF, we would have had a good time.

Since John's giving flowers can take place both yesterday and tomorrow, it is not obvious that John's giving flowers to Mary yesterday and his giving flowers to Mary tomorrow are mutually exclusive. In Kratzer's proposal, we would need to posit a more general fact and let it be an element of $f\left(w_{c}\right)$. For instance, in (14a), it might be "John can give flowers to Mary only once a year to celebrate her birthday." This would make John's giving flowers to Mary yesterday and John's giving flowers to Mary tomorrow mutually exclusive. Kratzer's account succeeds in accounting for why some propositions must be kicked out. However, assuming that we adopt Kratzer's proposal, we want to explain how focus facts are related to the selection of the function $f$ since the examples discussed in the paper are all focus-sensitive.

Rooth (1985) provides an account of focus effects in counterfactual conditionals on the basis of Kratzer's proposal. He examines Dretske's (1972) examples in (15) and concludes that the p-set (i.e., the set of alternative propositions) is used in each case to produce an existentially quantified proposition that is chosen by the partition function $f$ for the actual world $w_{c}$. The situation being entertained is one in which Clyde marries Bertha because being married at the age of thirty is the condition for being eligible for an inheritance.

a. If Clyde hadn't MARRIEDF Bertha, he would not have been eligible for the inheritance.

b. If Clyde hadn't married BERTHAF, he would not have been eligible for the inheritance.

For each example, we can obtain an existentially quantified proposition with a variable in the position of the focused expression after removing negation: (16a) for (15a), and (16b) for (15b). 
a. There is a relation $R$ such that $<$ Clyde, Bertha $>\in R$, where $R$ is one of the contextually salient relations.

b. There is an individual $\mathrm{x}$ such that Clyde married $x$, where $x$ is one of the contextually salient individuals.

Rooth claims that each proposition thus obtained is an element of $f\left(w_{\mathrm{c}}\right)$ for the relevant example. This means that the consequent of (15a) is evaluated with respect to a set of worlds in which Clyde dates but is not married to Bertha (for example). In this situation, it is correct to conclude that the counterfactual conditional is true. By contrast, (15b) is intuitively false because $f\left(w_{\mathrm{c}}\right)$ contains the proposition (16b). This means that the consequent in (15b) follows from the assumption that Clyde married someone other than Bertha. We can conclude that the counterfactual is false since as long as Clyde is married, he should be eligible for the inheritance regardless of who his spouse is. Although it seems artificial to remove negation before calculating the relevant $\mathrm{p}$-set, this proposal makes the right predictions for the examples (16a-b).

Let us now discuss the crucial examples (14a-b) in light of the KratzerRooth proposal. In order to do so, we must determine at least tentatively the semantic contribution of tense morphemes (in particular, that of the perfect). First, as far as the proposition conveyed by the antecedent is concerned, our intuition favors the idea of ignoring tense. Thus, we assume that the proposition conveyed by the antecedent in (14a) is that associated with "John gives flowers to Mary tomorrow." Second, Rooth's proposal dictates that an existentially quantified proposition obtained with a bound variable in the position of the focused expression be an element of $f\left(w_{c}\right)$. In (14a), the focused expression is the adverb tomorrow. As for the semantic contribution of the tense morphemes, let us leave open the possibilities and try out two options here. One possibility is to obtain an existentially quantified proposition as in (17a) and let it be an element of $f\left(w_{c}\right)$. Alternatively, we ignore tense morphemes and let (17b) be the existentially quantified proposition in question.

a. There is an interval $\mathrm{t}$ such that John gives flowers to Mary at $t$ and $t$ is a contextually salient past interval.

b. There is an interval $t$ such that John gives flowers to Mary at $t$.

Let us examine these two possibilities one by one. If we adopt the option (17a), we are led to an undesirable result because we must evaluate the consequent of (14a) in worlds in which John gives flowers to Mary at a past time (yesterday in our scenario) as well as tomorrow. On the other hand, if we adopt (17b), then no new information is added since it is entailed by the proposition conveyed by the antecedent, i.e., John gives flowers to Mary tomorrow. This also makes the wrong prediction. We would need to evaluate the consequent in worlds in which John gives flowers to Mary tomorrow. Unfortunately, this set of worlds includes those in which John gives flowers to Mary yesterday as well. According to our intuitions, Mary is not pleased (tomorrow) in such a world. However, the proposal predicts otherwise. This is an undesirable result. 


\section{Proposal}

In this section, I shall present a proposal to account for the above data. First, let us discuss the problem of a mismatch between the assumed semantic contribution of the tense form and that of the temporal adverb in $(14 a-b)$ : the perfect is understood to indicate anteriority, but the adverb tomorrow clearly denotes a future time. I believe that a solution to this problem is suggested by the oft voiced but rarely formalized claim that the contribution of past tense (in normal declarative sentences) is presuppositional in that it indicates a contextually specified past time interval that has already been introduced by the time the sentence is uttered. In a simple declarative sentence, the proposition it describes (i.e., the sentence less the tense morpheme) is asserted to obtain at this interval. ${ }^{9}$ I contend that the same is true of conditionals, except that the past interval indicated by the perfect (which we could assume has the role of a past tense morpheme) is not the time at which the proposition described by the antecedent of the conditional is true. Rather it is the time at which some proposition contrasted with the one specified by the antecedent is true (at least when some constituent in the antecedent is focused). This is the right generalization about the examples discussed so far. ${ }^{10}$ The truth conditions of past counterfactuals with a focused constituent in the antecedent can be given as in (18) in a preliminary fashion.

(18) The truth conditions for a sentence of the form "If DP 1 PAST PERF $3 \mathrm{VP}_{1}$, $\mathrm{DP}_{2}$ would $\mathrm{PERF}_{3} \mathrm{VP}_{2}$ " are given in the following way. Let $q$ be the denotation of " $\mathrm{DP}_{1} \mathrm{VP}_{1}$ " (tenseless), and $r$ the denotation of " $\mathrm{DP}_{2} \mathrm{VP}_{2}$ " (tenseless), where $q$ and $r$ are elements of $D_{<i,\langle s, t>\rangle}$. The entire conditional is true iff (i) the semantic object $p \in D_{<i,\langle s, t\rangle>}$ that is provided by the context and is contrasted with $q$ is such that $p\left(g_{c}(3)\right)\left(\mathrm{w}_{\mathrm{c}}\right)=1$ and for all maximal sets $X$ in $A_{w_{c}}(\{w \mid$ there is an interval $i$ such that $q(i)(w)=1\})$, $p\left(g_{c}(3)\right) \notin X$, and (ii) the proposition $\{w \mid$ there is an interval $i$ such that $r(i)(w)=1\}$ follows from every maximal set in $A_{w_{c}}(\{w \mid$ there is an interval i such that $q(i)(w)=1\})$.

Notation: $g_{c}=$ the value assignment provided in the context $c$ (e.g., $g_{c}(3)=$ the time interval that the index 3 denotes)

$D_{a}$ (where a is any type) $=$ the set of all possible denotations of type $a$

Put informally, (18) says that a past counterfactual is true iff (i) the proposition that is contrasted with the one conveyed by the antecedent is true at the contextually salient past time (indicated by the perfect) in the actual world, and (ii) the consequent is true in all those worlds that are consistent with what is the case in the actual one except that the antecedent is true and the proposition contrasted with it is false in those worlds. In (14a), the proposition that is contrasted with what the antecedent conveys is "John gave flowers to Mary yesterday." If a temporal adverb is in the antecedent, it either indicates the time of the relevant eventuality independently of the contextually salient past time denoted by the past perfect (e.g., tomorrow) or introduces a time in relation to this past time (e.g., the following day). If no adverb is present, we assume that there is a covert adverb then that indicates that the time of the antecedent eventuality is simultaneous with the contextually salient past time. (18) is descriptively adequate as far as the above data 
are concerned but is not very explanatory. In particular, it does not explain how we obtain the proposition that is contrasted with the one conveyed by the antecedent.

Let us see how this proposal deals with example (14a). (19) shows how its truth conditions are determined by (18).

【If John PAST PERF3 give flowers to Mary TOMORROWF, she would PERF3 be pleased $\rrbracket=1$ iff (i) John gives flowers to Mary at $g_{c}(3)$ (within yesterday) in $w_{c}$, and for all maximal sets $X$ in $A_{w_{c}}$ ( $\{w \mid$ John gives flowers to Mary tomorrow in $w\}),\left\{w \mid\right.$ John gives flowers to Mary at $g_{c}(3)$ (within yesterday) in $w\} \notin X$, and (ii) the proposition $\{w \mid$ Mary is pleased (tomorrow) in w $\}$ follows from every maximal set in $A_{w_{c}}(\{w \mid$ John gives flowers to Mary tomorrow in $w$ \}).

According to (19), the truth condition of (14a) is that John gave flowers to Mary yesterday in the actual world, and Mary would be pleased in those possible worlds in which John gives flowers to her tomorrow and not yesterday. This corresponds to the intuitive meaning of (14a).

Given the preliminary analysis of counterfactuals in (18), I am now in a position to present the core ideas in our proposal, which is intended to account for the semantics of counterfactuals containing focused constituents. According to my proposal, the particular proposition that is contrasted with the one conveyed by the antecedent is obtained via focus. To be more specific, I contend that the default semantic effect of focused constituents in the antecedent of a counterfactual conditional is obtained through the adverb instead. It is possible to use a phrase of the form instead of DP overtly to introduce the contrasted counterpart as in (20ab).

a. If John had given flowers to Mary TOMORROWF instead of yesterday, she would have been pleased.

b. If JOHNF had given flowers to Mary instead of Bill, she would have been pleased.

The idea I pursue in this paper is that the semantics of instead interacts with focus even when it is not there overtly. I assume with Rooth (1992) that focusing causes a focus operator and a variable to be introduced as a sister node to an expression that contains a focused constituent in the syntactic representation. Then we can impose a constraint upon the relation between the ordinary denotation of the focused phrase and its associated variable $C$.

(21) Where $\phi$ is a syntactic phrase and $C$ is a syntactically covert semantic variable, $\phi \sim C$ introduces the presupposition that $C$ is a subset of $\llbracket \phi \rrbracket^{f}$ (the focus semantic value of $\phi$ ) containing $\llbracket \phi \rrbracket^{o}$ (the ordinary semantic value of $\phi)$ and at least one other element. (Rooth 1996: 279)

In the case of (1a), we can assume that its antecedent is syntactically represented as in (22). Let us assume that the tense is ignored for the purpose of calculating the ordinary and focus semantic values of the antecedent of a conditional. The tense (i.e., the perfect) constrains $C$, as we shall see below. 


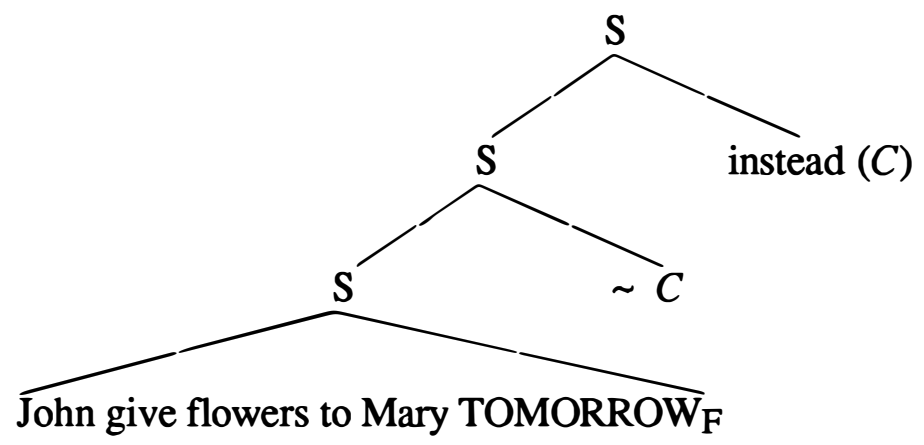

In order to leave open the possibility that the temporal location of the eventuality described in the sentence be specified further, I assume that each sentence denotes an element of $D_{<i,<s, t>>}$, i.e., a function from intervals to functions from worlds to truth values. Accordingly, $C$ is an element of $D<<i,\langle s, t>>, t>$. I refer to semantic objects of this type as "temporally indeterminate propositions" in order not to confuse them with "regular" propositions, which are sets of worlds (i.e., elements of $\left.D_{<s, t>}\right)$ for our purposes. ${ }^{11}$ The focus semantic value of John give flowers to Mary TOMORROWF is the set of temporally indeterminate propositions of the form "John give flowers to Mary $\mathrm{X}$," where $X$ is a temporal adverb like tomorrow. $C$ must denote a subset of this set and must contain the temporally indeterminate proposition "John give flowers to Mary tomorrow" and at least one other temporally indeterminate proposition. In the scenario introduced above, $C$ should contain exactly two temporally indeterminate propositions: "John give flowers to Mary yesterday" and "John give flowers to Mary tomorrow." The meaning of instead is specified as in (23).

instead translates as $\lambda f_{<<i,<s, t>>, t>}\left[\lambda p_{<i,<s, t>>}\left[\wedge\left[\exists t_{1}\left[\vee\left[p\left(t_{1}\right)\right]\right] \wedge\right.\right.\right.$ $\left.\left.\forall q_{<i,<s, t>>}\left[[f(q) \wedge q \neq p] \rightarrow \neg \exists t_{2}\left[\vee\left[q\left(t_{2}\right)\right]\right]\right]\right]\right]$

Notation: $f<\langle i,\langle s, t>>, t>=$ a variable of type $\langle<i,\langle s, t>>, t>$ (set of temporally indeterminate propositions)

$p<i,\langle s, t\rangle>=$ a variable of type $\langle i,\langle s, t\rangle>$ (temporally indeterminate proposition), similarly for $q_{<i,<s, t>>}$

$i=$ the type of time intervals; $s=$ the type of worlds; $t=$ the type of truth values

${ }^{\wedge} \phi$ (where $\phi$ is of type $t$ ) is an expression of type $\langle s, t>$, i.e., proposition

${ }^{\vee} \mathrm{p}$ (where $\mathrm{p}$ is of type $\langle s, t\rangle$ is an expression of type $t$, i.e., sentence

(22) then means that John gives flowers to Mary tomorrow and all other temporally indeterminate propositions in $C$ are such that no time makes them true (i.e., John did not give flowers to Mary yesterday). Let us see how this analysis of focus in counterfactuals combines with our preliminary analysis of counterfactuals given in (18).

The perfect in the antecedent indicates the existence of some relevant eventuality at a contextually salient past time. In the examples we discussed above, the relevant eventuality is one that obtains in the actual world and is contrasted with the one described by the antecedent. Thus, (18) is descriptive adequate. However, some counterfactual conditionals have a true antecedent clause. (24) is one such example due to Anderson (1951:37). 
If Jones had taken arsenic, he would have shown just exactly those symptoms which he does in fact show.

Although the word arsenic receives a focal stress, it does not seem to produce a clear semantic effect normally associated with focus. In other words, it does not seem to say that Jones took arsenic instead of something else. If the default interpretation of a focused expression in the antecedent of a conditional were always made available via the adverb instead, we would not expect this consequence. 12 Another point to be noted here is that when we say that the antecedent of (24) is true, this can only mean that it is true at the contextually salient past time indicated by the perfect. For example, it is hard to interpret (25) in such a way that Jones actually took arsenic at the time indicated by the temporal adverb the following day.

If Jones had taken arsenic THE FOLLOWING DAYF, he would have shown just exactly those symptoms which he does in fact show.

This shows that when the antecedent describes an eventuality that obtains at a time different from the past time indicated by the perfect, then the conditional is truly counterfactual in that the antecedent must describe a contrary-to-fact situation. In this case, we must posit a (temporally indeterminate) proposition that is not described by the antecedent and is true at the contextually specified past time in the real world. On the other hand, when the antecedent is true at the past time in the actual world, there is no need to find such a proposition. Our task is to obtain these generalizations in a principled manner.

To account for the data we have discussed so far, I revise (18) and present it here as in (26).

(26) The truth conditions for a sentence of the form "If DP 1 PAST PERF $3 \mathrm{VP}_{1}$, $\mathrm{DP}_{2}$ would PERF $3 \mathrm{VP}_{2}$ " are given in the following way. Let $q$ stand for $\llbracket \mathrm{DP}_{1} \mathrm{VP}_{1} \rrbracket^{\mathrm{o}}$ (tenseless), and $r$ stand for $\llbracket \mathrm{DP}_{2} \mathrm{VP}_{2} \rrbracket^{\mathrm{o}}$ (tenseless), where $q$ and $r$ are elements of $D_{\langle i,\langle s, t>\rangle}$. The entire conditional is true iff (i) there is a $p \in C$ (where $\left.p \in D_{<i,\langle s, t>\rangle}\right)$ such that $p\left(g_{c}(3)\right)\left(w_{c}\right)=1$ and for all maximal sets $X$ in $A_{w_{c}}(\{\mathrm{w} \mid$ there is an interval $i$ such that $q(i)(w)=1\}), p\left(g_{c}(3)\right) \notin$ $X$, and (ii) the proposition $\{w \mid$ there is an interval $i$ such that $r(i)(w)=1\}$ follows from every maximal set in $A_{w_{c}}(\{w \mid$ there is an interval $i$ such that $q(i)(w)=1\})$.

The main revision here is that the temporally indeterminate proposition $p$ could be the one expressed by the antecedent or any other element in $C .{ }^{13}$ If it happens to be the one expressed by the antecedent, then the antecedent is true in the actual world, and there is an eventuality described by it in the past. If $p$ is not the one expressed by the antecedent, then some other element of $C$ is true at the contextually salient past time. We can easily verify that when there is a tense-adverb mismatch as in $(14 \mathrm{a}-\mathrm{b})$, it is guaranteed that it has to be an instance of a truly counterfactual conditional in that the proposition expressed by the antecedent is false in the actual world.

This account still does not explain why in (24), no eventuality seems to be contrasted with Jones's taking arsenic. I can think of two possible replies. One is that (24) may be used to contrast Jones' taking arsenic with his taking nothing (or 
no arsenic). If so, this alternative possibility does not seem to be salient enough to strike us as a real alternative. Another possibility is that compared to the case of "genuine counterfactuals," examples like (24) impose only trivial requirements upon the elements of $C$ other than the one the antecedent denotes. To be more specific, all alternatives to "Jones took arsenic" are merely required to be false in the actual world. However, this is assumed to be the case anyway because of pragmatic considerations, thereby making these alternatives inconspicuous. By contrast, when the antecedent is false in the actual world as in (14a), at least one of the alternatives is required to satisfy two conditions: (i) being false in those worlds that are relevant to the examination of the consequent, and (ii) being true in the actual world at the relevant past time. Thus, those alternatives are salient. This account is not definitive but hopefully serves as a first approximation.

This proposal accounts for non-temporal counterfactuals, too. For example, in (27a) $C$ is a subset of the focus semantic value of $J O H N_{F}$ give flowers to Mary. Similarly, in (27b), $C$ is a subset of the set of temporally indeterminate propositions of the form "John give X to Mary." Also it may be instructive to note here that the set of temporally indefinite propositions $C$ does not have to be a set with exactly two elements. For example, we could assume with regard to (27a) that Bill and Fred gave flowers to Mary without success. In this case, $C$ contains three temporally indeterminate propositions: "John give flowers to Mary", "Bill give flowers to Mary", "Fred give flowers to Mary." A possible scenario in (27b) is that John gave books and CDs to Mary without success. A similar story can be constructed with regard to temporal examples as well.

(27) a. If JOHNF had given flowers to Mary, she would have been pleased.

b. If John had given FLOWERS F $_{\text {to }}$ Mary, she would have been pleased.

Note also that the semantic proposal about instead in (23) can be used in simple (non-conditional) sentences as well.

John dated MARYF instead.

(28) means that John dated Mary and all relevant propositions of the form "John dated $x$ " are false except where $x=$ Mary. Thus (23) makes the right prediction here as well.

\section{A Different Type of Association with Focus: too and as well}

In discussing the projection problem of presuppositions in conditionals, Heim (1992) notes that there are two different types of focus effects when the antecedent of a conditional has a focused constituent. One is the type we have so far considered. However, there is another type where the proposition given in the antecedent does not kick out the presupposed presupposition; rather the new proposition is simply added to what is already assumed. Consider the examples in (29). 
(29) a. If John had invited MARYF, too, the party would have been fun.

b. If $\mathrm{JOHN}_{\mathrm{F}}$ had joined the club as well, everybody would have been pleased.

These examples can be dealt with as instances of association with focus. The only difference with the earlier examples is that in $(29 \mathrm{a}-\mathrm{b})$ too or as well is associated with focus. I posit the semantics of too or as well as in (30).

$$
\begin{aligned}
& \text { too or as well translates as } \lambda f_{<<i,<s, t>>, t>}\left[\lambda p _ { < i , < s , t > > > } \left[\wedge \left[\exists t_{1}\left[\vee\left[p\left(t_{1}\right)\right]\right] \wedge\right.\right.\right. \\
& \left.\left.\left.\exists q<i,<s, t>>\left[f(q) \wedge q \neq p \wedge \exists t_{2}\left[\vee\left[q\left(t_{2}\right)\right]\right]\right]\right]\right]\right] \\
& \text { Note: See (23) for the notational conventions adopted here. }
\end{aligned}
$$

It is easy to verify that (30) gives us the right results for examples like (29a-b). For instance, the proposal says that if we suppose counterfactually that John had invited Mary in addition to someone John actually invited, then the party would have been fun. Similarly for (29b).

What this shows is that the semantic effect associated with the default adverb instead can be overridden when expressions such as too or as well are present.

\section{Some Examples from Japanese}

The phenomena we have discussed in this paper are found cross-linguistically. As an example, let us take up Japanese. Japanese conditionals exhibit many different combinations of tense and aspect forms, and it is not easy to find a pattern in their behavior. However, the semantic distinction characterized in English in terms of counterfactual vs. indicative conditionals alluded to above is also found in Japanese and is overtly marked morphologically. Consider (31a-b).

a. Mosi ASITAF John kara hana-o morat-ta ra, if tomorrow John from flower-ACC receive-PAST Mary-wa yorokon-da daroo(-ni). Mary-TOP be-pleased-PAST probably regrettably 'If Mary had received flowers from John tomorrow, she would have been pleased.'

b. Mosi ASITAF John kara hana-o more-ta ra, if tomorrow John from flowers-ACC receive-PAST Mary-wa yorokobu daroo.

'If Mary receives/received flowers from John tomorrow, she would be pleased.'

Note: The combination of mosi and -ra roughly corresponds to the meaning of if or supposing in English.

Note that in both (31a) and (31b) the antecedent clause is in the past tense. As the English glosses show, (31a) receives a counterfactual interpretation, whereas (31b) receives an indicative-like interpretation. What sets them apart is the tense form in the consequent. (31a) has a past tense morpheme (plus the optional morpheme $-n i$ 'regrettably'), which indicates that the entire conditional receives a counterfactual 
interpretation. (31b), on the other hand, contains a present tense form, which is often invoked to indicate a situation temporally located in the future. For the purpose of this paper, I will not attempt to propose a compositional relationship between various tense forms and their semantic interpretation possibilities in Japanese conditionals. One situation in which (31a) can be used felicitously corresponds exactly to the situation in which (14a) can be used in English. Two times are compared and contrasted in this case. Another acceptable scenario is one in which the speaker somehow "knows" (or firmly believes) that Mary will not receive flowers from John tomorrow. For example, it can be used when John intended to give flowers to Mary tomorrow to celebrate her birthday but was killed in a traffic accident last week. In this case, there is no sense in which John's giving flowers to Mary tomorrow is compared to any other event or situation that actually took place in the past. The point is rather that "John gives flowers to Mary tomorrow" is already established at the utterance time of (31a) as a false proposition. The English counterpart (14a) does not seem to be acceptable in this type of situation. In contrast, (31b) is used when Mary's receiving flowers from John is not predetermined but is also not precluded. Thus, it is like future less vivid or future neutrally vivid conditionals in English.

Although there are some differences between English and Japanese regarding the behavior of counterfactual conditionals, both languages can express counterfactuals about the future. Thus, the phenomena discussed in this paper are not esoteric facts that only concern English.

\section{A Possible Difference between Counterfactual and Indicative Conditionals}

Our proposal also points to one possible difference between counterfactual conditionals and indicative conditionals. Counterfactual conditionals with a focused constituent can be used to identify a presupposed proposition that is removed for the purpose of processing the consequent. In contrast, indicative conditionals with a focused constituent can only introduce a presupposition obtained by existentially quantifying over the variable posited in the position of the focused expression, which is compatible with what the antecedent states. Consider examples like (32ab).

(32) a. If JOHNF had given flowers to Mary, she would have been pleased.

b. If JOHNF gave flowers to Mary, she must have been pleased.

In (32a), the above proposal predicts correctly that there is some proposition of the form 'X give flowers to Mary (at a past salient interval)' that must be false in the worlds that are used to examine the consequent. In other words, instead is associated with focus. By contrast, the strongest assumption that we can make with respect to (32b) is that it presupposes the existentially quantified proposition $\exists x$ [ $x$ gave flowers to Mary]. This may be an important difference between counterfactual conditionals and indicative conditionals. 


\section{Conclusion}

In sum, this paper proposes the following: (i) The perfect in the antecedent of a past counterfactual requires that one of the alternative semantic values of the antecedent (temporally indeterminate propositions) is true in the actual world at the past time specified by the context; (ii) When such expressions as too or as well are missing, the semantics of focused constituent in the antecedent of a counterfactual conditional (including the case of focused temporal adverbs) is accounted for as an instance of association of focus involving the adverb instead. My account is made within the alternative semantics theory for focus proposed by Rooth (1985. 1992) and Kratzer's $(1981,1989)$ account of counterfactuals.

\section{Endnotes}

* I thank Kai von Fintel, Irene Heim, James Higginbotham, Sabine Iatridou, Angelika Kratzer, Yuki Matsuda, Shigeru Miyagawa, Uli Sauerland, Roger Schwarzschild, and other participants of SALT 10 for comments and discussions. All errors are mine.

${ }^{1}$ It has been claimed that the falsity of the antecedent is not a presupposition but is an implicature. This is because the antecedent of a conditional is not always false in the actual world.

2 I believe that it is more accurate to say that the perfect establishes a past interval within which a relevant eventuality obtains. However, for the sake of simplicity, I will assume for the purpose of this paper that the contextually salient interval is the time at which a relevant eventuality obtains. See Ogihara (1996) for relevant discussion.

3 The examples are not Lewis's but preserve the tense configurations of his original.

4 There may be a different way of interpreting the semantic contribution of the perfect (Roger Schwarzschild, personal communication). According to Iatridou (2000), the perfect is used to indicate anteriority. But given the fact that the perfect is capable of indicating anteriority in relation to a time other than the utterance time, one might assume that the perfect does not mean "prior to the utterance time" but means "prior to some (possibly future) reference time." On this conjecture, (1a) means approximately the following: If we assume counterfactually that at some time tomorrow John has already given flowers to Mary, she has been pleased at the time. Even if this were a possible interpretation, it would not capture the point of the counterfactual (1a). Although (1a) posits a counterfactual situation located in the future (i.e., tomorrow), the conditional also makes reference to the past, though in a covert way.

5 The term "eventuality" coined by Bach (1986) is intended to cover both events and states.

6 This is a rough generalization and is not accurate because there are some counterfactual conditionals that have a focused expression in the antecedent and yet are true (in the actual world). This point will be discussed in Section 3.

${ }^{7}$ Given that $D_{s}$ is the set of possible worlds, $D_{e}$ the set of individuals, and $D_{t}$ the set of truth values, $f$ is an element of $D_{\langle s,<<s, t>, t>>}$ (i.e., the set of all possible denotations of type $\langle s,\langle<s, t>, t\rangle>$ ). 
8 A set $\mathrm{X}$ is a maximal set in $Y$ iff there is no $Z \in Y$ such that $X$ is a proper subset of $Z$ (i.e., iff $Y$ has no superset of $X$ ). See Kratzer (1981) for a more complex version where she does not assume the existence of maximal sets in $A_{w}(p)$.

9 See Heim (1994).

10 We will discuss a counterexample to this generalization below.

11 Kaplan (1977:503) refers to propositions construed as sets of worlds as "temporally specific" propositions.

12 This point is due to Kai von Fintel (personal communication).

13 This requirement may not be strong enough, but I leave this possible problem for future inquiry.

\section{References}

Anderson, Alan Ross (1951) 'A Note on Subjunctive and Counterfactual Conditionals', Analysis 12, 35-38.

Bach, Emmon (1986) 'The Algebra of Events', Linguistics and Philosophy 9, 516.

Dretske, Fred (1972) “Contrastive Statements," Philosophical Review 81, 41137.

Heim, Irene (1992) 'Presupposition Projection and the Semantics of Attitude Verbs', Journal of Semantics 9, 183-221.

Heim, Irene (1994) 'Comments on Abusch's Theory of Tense.' in H. Kamp (ed.) Ellipsis, Tense and Questions, Dyana 2 Deliverable, 143-170.

Iatridou, Sabine (2000) 'The grammatical ingredients of counterfactuality', Linguistic Inquiry 31, 231-270.

Kaplan, David (1977) 'Demonstratives: An Essay on the Semantics, Logic, Metaphysics, and Epistemology of Demonstratives and Other Indexicals', manuscript. Published in Joseph Almog, John Perry and Howard Wettstein (eds.), Themes from Kaplan, 1989, Oxford University Press, New York, 481-614. [Page references in the text are made to the published version.]

Kratzer, Angelika (1981) 'Partition and Revision: The Semantics of Counterfactuals', Journal of Philosophical Logic 10, 201-216.

Kratzer, Angelika (1989) 'An Investigation of the Lumps of Thought', Linguistics and Philosophy 12, 607-653.

Lewis, David. (1973) Counterfactuals, Harvard University Press, Cambridge, Massachusetts.

Ogihara, Toshiyuki (1996) Tense, Attitudes, and Scope, Kluwer, Dordrecht.

Rooth, Mats (1985) Association with Focus, Ph.D. dissertation, UMassAmherst.

Rooth, Mats (1992) 'A Theory of Focus Interpretation', Natural Language Semantics 1, 75-116.

Rooth, Mats (1996) 'Focus', in S. Lappin (ed.), The Handbook of Contemporary Semantic Theory, Blackwell, Oxford.

Stalnaker, Robert (1968) 'A theory of Conditionals', in N. Resher (ed.), Studies in Logical Theory, Blackwell, Oxford. 